Revista

A Cor

das Letras

\title{
Fernão Mendes Pinto, cronista de viagem ou prosador de ficção?
}

\author{
Fernão Mendes Pinto, travel writer or fiction writer?
}

Cid Seixas*

Universidade Estadual de Feira de Santana

Feira de Santana, Bahia, Brasil

\begin{abstract}
Resumo: As leituras da obra de Mendes Pinto giram em torno de duas vertentes: uma que vê ironia e crítica à hipocrisia do mundo cristão e outra que descarta a natureza satírica do texto, entendido como expressão do pensamento cristão no Renascimento português.
\end{abstract}

Palavras-chave: Peregrinação. Ironia. Sátira. Cristianismo

\begin{abstract}
The readings of Mendes Pinto's work revolve around two aspects: one that sees irony and criticism of the hypocrisy of the Christian world and another that discards the satirical nature of the text, understood as an expression of Christian thought in the Portuguese Renaissance.
\end{abstract}

Keywords: Peregrinação. Irony. Satire. Christianity.

A revisão crítica da Peregrinação de Fernão Mendes Pinto pelos estudiosos da segunda metade do século XX teve, a princípio, a tendência de emprestar a esse livro ainda mais deslumbramento que o olhar do viajante experimentou. Se a escrita já sugere lances de ironia e de fina percepção dos equívocos e desvarios da sociedade portuguesa quinhentista, estudiosos como (1978, 1981, 1983) ou Antonio José Saraiva (1971) desentranharam das suas leituras ainda mais vislumbres de ironia e consciência crítica.

Opondo-se à tese até então aceita segundo a qual a Peregrinação é uma sátira impiedosa das práticas de proveito e hipocrisia do cristianismo português quinhentista, perfilam-se estudiosos como Aníbal Pinto de Castro, em Portugal, e, mais recentemente, Francisco Ferreira de Lima, no Brasil.

A direção apontada por Rebecca Catz, ao afirmar que Mendes Pinto não tinha o cristianismo como modelo, é refutada com veemência, especialmente quando essa estudiosa, apesar da precariedade das provas arroladas, conclui que o autor da Peregrinação era judeu e, como tal, teria desenvolvido nuances de crítica e de ironia que somente uma leitura fina como a sua desvendaria, séculos mais tarde. Ela acreditava ler aquilo que o autor pretendia que se lesse.

O excesso de deslumbramento no olhar de um ou de outro estudioso suscitou a revisão dos pontos de vista tradicionalmente aceitos. Hoje, na esteira da refutação dos

* Doutor em Letras pela Universidade de São Paulo e Professor Adjunto da Universidade Estadual de Feira de Santana. E-mail: cidseixas@yahoo.com.br. 
pressupostos mais fantasiosos, especialmente os de Catz, a evidente natureza polissêmica da escritura de Mendes Pinto é obscurecida, ou negligenciada, pelos estudos que pretendem devolver ao texto a sua "verdadeira dimensão". O propósito de evitar os excessos de deslumbre exigiu uma análise pertinente e rigorosa do contexto social quinhentista, onde a Peregrinação é considerada principalmente como documento. $\mathrm{O}$ documento de viagem que sempre pareceu aos leitores dos séculos passados.

Numa tal perspectiva, aqui chamada de revisionista, essa obra não veria mais do que a sua época costumava ver. Ela não seria a sátira impiedosa nem a crítica irônica dos valores religiosos e éticos então vigentes. Aquilo que queremos ler, quando lemos o texto de Mendes Pinto, não pertenceria a ele, mas à nossa ideologia de leitores. Ainda segundo esse ponto de vista, a diferença de perspectiva imposta pelas ideias do nosso século estaria interferindo no sentido da obra estudada.

Mas será que isso é indesejável? Será que o significado de uma obra é apenas constituído pelo momento da sua produção? E não, também, pelo da sua recepção?

O que importa numa obra literária é a intenção do autor ou aquilo que o texto diz, mesmo sem intenção de dizer?

A permanência e a atualidade da Peregrinação são devidas, principalmente, a sua falta de sinceridade. Isto é, à sua natureza ficcional, onde os fatos vividos por um personagem real chamado Fernão Mendes Pinto, mais os fatos sonhados e inventados, e os fatos vividos por outros viajantes, são todos reunidos num mesmo personagem ficcional chamado também de Fernão Mendes Pinto.

Ora, se o autor pressentia, ou mesmo, se tinha uma certa consciência de que estava fazendo ficção - para falar com mais propriedade de uma realidade que não cabia nos estreitos limites da realidade estabelecida -, ele bem que poderia não ser sincero nas suas ingênuas genuflexões diante de uma prática impiedosa que correspondia ao discurso cristão mais piedoso da sua época.

Tratamos aqui, portanto, da questão da intenção do autor, apesar do sentido da obra não ser um servo fiel da sua intenção consciente. Como a crítica revisionista trabalha no nível dessa consciência cristã do século XVI, a sua leitura da Peregrinação pode não ser a mesma do leitor comum dos nossos dias, que estaria mais próximo do entusiasmo; mesmo do entusiasmo de Rebecca Catz.

Observe-se que o critério de objetividade presente na abordagem revisionista se, por um lado, é capaz de recuperar e reconstituir o quadro das ideias do século XVI, por outro lado, pode implicar uma leitura menos polissêmica, menos literária, portanto; e mais científica. Isto é: uma leitura do ponto de vista de uma sociologia das ideias, de uma teoria das ideologias, ou de uma sociologia do conhecimento.

Pergunto então: essa leitura metodologicamente estruturada visando compreender a verdade do viajante não negaria, não desconheceria, a natureza literária do texto? $\mathrm{O}$ texto literário não seria, quase sempre, uma dissimulação? Por que então aceitá-lo como confissão verdadeira?

Aquele trapacear com a linguagem do qual o velho Barthes $(1951,1972)$ fala com muita propriedade não estará excluído da Peregrinação, se ela for lida como um texto que testemunha e dá fé de uma verdade? 
O que restará desse texto - o texto que Mendes Pinto escreveu e que nós lemos como literário - sem as suas possíveis dissimulações?

Enfim: é legítimo analisar um texto, considerado pela tradição como literário, a partir de critérios capazes de descarnar os sentidos circundantes, aderentes ao sentido por acaso previsto - ou imprevisto - pelo autor?

Desde a sua publicação, em 1614, que essa obra, deslocada do contexto documental das narrativas de viajantes, passou a ser vista como um dos tantos relatos de viagem. Por isso, a ingênua glosa do seu nome:

- Fernão, Mentes?

- Minto.

Fernão Mendes Pinto era tomado como uma testemunha ocular e infiel. Mas quando nos colocamos diante de uma escolha: continuar lendo a Peregrinação como simples relato de viagem ou passar a lê-la como prosa de ficção, como obra de arte verbal, portanto, os critérios de análise precisam ser revistos. E isso faz diferença. Se aceitarmos que o Fernão Mendes Pinto que aparece como narrador de tantas maravilhas, ao contrário de toda a expectativa dos seus leitores dos séculos anteriores, não é o mesmo sujeito civil que escreveu o livro, mas um personagem de ficção literária e, como queria Aristóteles, universal, resultado de muitas experiências de muitos sujeitos, as considerações a respeito do seu compromisso com o ideal cristão requerem outro tom de abordagem e outro modo de compreensão.

Veja-se que no episódio da Ilha dos Ladrões, Mendes Pinto e seus companheiros portugueses roubam uma embarcação e depois celebram o crime agradecendo a Deus por mais uma graça. Um menino tomado prisioneiro, um não-cristão, portanto, faz uma severa crítica àqueles que atribuem a um milagre de Deus o bem-sucedido roubo.

Ao se incluir entre aqueles que são censurados pelo menino, cabem aqui duas conjecturas, o personagem-narrador Fernão Mendes Pinto seria a universalização, no sentido aristotélico, de todo viajante, e esse menino seria a consciência crítica do autor e de todo cristão que conseguisse ultrapassar a ética da conveniência.

Ao reunir num personagem traços gerais, universalizando-o, portanto, o autor da Peregrinação estaria plenamente no território da ficção. É o que se dá com Antonio de Faria, representação coletiva de todo português que empreende a viagem e os saques dessa "cavalaria marítima" (conforme a expressão cunhada por Francisco Ferreira de Lima (1998) e legitimada por Massaud Moisés). O destino desse personagem seria assim uma advertência e uma crítica aos contemporâneos. Não importa tenha existido ou não um Antonio de Faria real. O que importa é o Antonio de Faria universal, construído pelo texto ficcional para servir de objeto da sua crítica.

Entendido desse modo, como um personagem de ficção que universaliza as ações de vários viajantes portugueses, o protagonista Fernão Mendes Pinto seria também um Antonio de Faria, como querem alguns estudiosos. Ou ainda, os personagens Fernão Mendes Pinto e Antonio de Faria seriam desdobramentos ficcionais de um mesmo sujeito real; ou, por outro lado, seriam uma bipartição de vários tipos e sujeitos da sociedade da época. 
No trecho da Peregrinação em que o viajante destaca a perfeição da justiça chinesa pelo fato dela se sustentar em juízes independentes, bons e justos, ele conclui que pobres e ricos, ilustres ou desconhecidos são julgados com isenção. Como o autor desse livro de viagens no país das maravilhas pertencia à classe dos novos servos (não mais da terra e sim do capital), esse "testemunho verdadeiro" nos mostra como o condão do discurso ficcional realiza um desejo das classes subalternas da Europa do século XVI.

Assim entendido, como personagem ficcional, Fernão Mendes Pinto pode legitimamente figurar entre os primeiros portugueses a desembarcar no Japão, não obstante o sujeito civil que escreveu a Peregrinação não figure entre esses. Assim ele pode sobreviver a todos os naufrágios e se fazer presente aos mais insólitos acontecimentos. Acontecimentos cuja recorrência e cuja dinâmica dificilmente cobririam a vida de um homem. É um excesso de fatos, é um excesso de atos, é um excesso de real para os limites de uma única vida. Somente recriada através da arte, da ficção, uma vida conteria tanto real.

Mas a Peregrinação tanto vem sendo lida como um verdadeiro relato de viagem, quanto como sendo uma obra de ficção que finge fazer um relato verdadeiro. Lida a obra como um relato (assim liam aqueles que acusavam o autor de mentiroso), a hipótese de o texto conter ironia ou crítica à ideologia das cruzadas transplantadas para a aventura marítima pode ser contestada. Observe-se bem: lida a obra como um relato, a hipótese do texto conter ironia e crítica severa à moral cristã do expansionismo pode ser contestada. Mas lida a Peregrinação como uma obra de arte literária, todo sentido possível de ser atribuído deve ser visto como possível; e não como impossível.

Os investigadores que procuram o nome de Fernão Mendes Pinto entre os marinheiros portugueses que pisaram pela primeira vez no Japão se inscrevem entre aqueles que tomam esse livro emblemático como um mero relato de viagem, sem levar em conta a passagem do documento à criação ficcional operada pela escritura do autor. Num momento de constituição plena do fazer literário e de redefinição dos gêneros, como o século XVI, um grande número de obras situa-se no território da prosa doutrinária, conceitual, informativa etc., sendo importante observar os momentos de ruptura entre o verdadeiro e o verossímil. Entre a prosa de formação (ou mesmo de informação) e a prosa de ficção.

A partir de tal perspectiva, compreende-se, inclusive, a ambivalência das situações apresentadas na Peregrinação. Mesmo sendo um cristão, um português do século XVI, o narrador-personagem dirige a sua crítica contundente à moral do proveito. Ao tempo em que o exemplo dado pelo outro desnuda os vícios que condimentam a ética cristã de então, a possibilidade do proveito justifica tais vícios e estabelece o círculo imaginário de pecado e de expiação.

Por isso, o depoimento mordaz e irrespondível contido nas situações e diálogos da Peregrinação. Enquanto tantas outras narrativas de viagem dão relevo à estranheza do outro, sem que isso implique o desnudamento dos vícios do conquistador, essa obra vale-se do confronto para sublinhar o que está em desacordo com o bom senso não apenas no outro mas, principalmente, no mesmo - isto é, no cristão, no europeu, no português. 
É verdade que o sujeito que conta as desaventuras assume o discurso do cristão português lançado aos mares temperados pela defesa da fé. É verdade também que a ambição é justificada pela legitimidade do proveito decorrente das missões destinadas a expandir as fronteiras da cristandade. E que toda conquista unia a espada à cruz.

Mas o narrador não oculta nem minimiza os fatos que contradizem os piedosos e frágeis propósitos. A cobiça, o desrespeito, o desamor e a deslealdade são evidenciados na sua ação e na dos seus companheiros, em flagrante contraste com a boa fé do outro. O outro, quase sempre, é pretexto para corrigir os costumes do mesmo.

Quando, em 1726, Jonathan Swift, em Gulliver's travels, se vale dos manuscritos que lhe foram confiados por um incerto Sr. Lemuel Gulliver para colocar a nu, para desvestir a máscara que cobria os gestos insensatos dos seus concidadãos, ele estaria retomando uma estratégia já usada na Peregrinaşão de sublinhar as virtudes do outro como forma de evidenciar os próprios defeitos.

A presença de um capitão português, Dom Pedro de Mendes, fechando as viagens de Gulliver - e, graças ao entendimento e aos modos desse capitão Mendes, reconduzindo Lemuel Gulliver à convivência dos homens - seria um indício de que Swift teria lido a Peregrinação como uma sátira e uma crítica aos vícios da cristandade. O próprio Janathan Swift, doutor em Teologia, tornou-se cônego para não viver na miséria, e depois, deão da Catedral de São Patrício, na Irlanda, não obstante tenha dedicado uma das suas obras ao ataque frontal ao desregramento da vida religiosa.

Partindo de quem não via com generosidade a espécie humana, a referência generosa a esse capitão Mendes, feita por Swift, seria uma simples coincidência, ou fruto da identidade entre dois autores?

Um, no século XVI, partindo de uma narrativa de viagem real para chegar à ficção, como de fato chegou, e outro, no século XVIII, valendo-se da ficção para criar a realidade de um verossímil viajante inglês.

Curioso ainda é o temor que Gulliver manifesta à Inquisição, quando da sua estadia em Lisboa. Essa emblemática presença do capitão Mendes no desfecho das viagens do capitão Gulliver sugere o tráfico de idéias comuns. Sugere mais ainda: analogamente, o possível risco que o autor-personagem da Peregrinação corria perante a Inquisição portuguesa; risco aqui traduzido no temor de Lemuel Gulliver.

De volta ao texto de Fernão Mendes Pinto, observe-se que o episódio ocorrido em Formosa, então conhecida como Ilha dos Léquios, mostra como os portugueses, acusados e tornados prisioneiros, são tratados com respeito por aqueles que o irão julgar. $\mathrm{O}$ governador inicia o interrogatório pedindo desculpas pela sua obrigação de levar o processo adiante e, movido pela compaixão, afirma que preferia estar no lugar dos prisioneiros. O interrogatório, feito por aqueles que - conforme a ótica cristã desconhecem a palavra divina, é uma eloquente lição de humildade e de sentimento cristão. A miséria dos prisioneiros portugueses compadece de tal modo os léquios que foram recolhidas esmolas suficientes que torná-los providos "de todo o necessario em tanta abastança, que não onue nenbum de nós que não trouxesse de cem cružados para cima". (PINTO, 1614, p. 131) 
Libertados com generosidade e tratados como amigos, o narrador e seus companheiros opõem a fidalguia dos léquios, desvalidos da palavra de Cristo, à vilania dos portugueses, piedosos cristãos:

Desta breue informação que tenho dado destes Lequios se pode enteder, \& assi o cuydo eu pelo que vy, que com quaisquer dous mil homes se tomara e senhoreara esta ilha com todas as mais destes acipelagos, donde resultara muyto mayor proueito q o que se tira da India (PINTO, 1614, p. 223).

A oposição gritante entre o espírito elevado dos léquios e a astuta mesquinharia dos cristãos não pode ser casual. Ao por na boca do narrador falas aparentemente "inocentes" que denunciam a mais absoluta ausência de ética, Mendes Pinto quer, de fato, se valer da ironia para criticar a moral da sua gente. A mesma moral que lhe constitui como sujeito e lhe contamina. Daí, a ambivalência.

Ao pintar o quadro com tintas carregadas e finalizar a pintura louvando a Deus pelo ocorrido, quando o ocorrido desafia a bondade divina, não estaria Mendes Pinto satirizando?

Para Francisco Ferreira de Lima, um dos mais abalizados representantes dessa nova corrente de releitura da Peregrinação, a frequência com que o narrador apela a "Cristo", a "Jesus", a "Nosso Senhor Jesus Cristo", ao "filho de Deus que morreu na Cruz" neutraliza a presença de ironia. Seu argumente parte do pressuposto segundo o qual, sendo um bom cristão, o autor não assumiria um discurso de arremedo dos cacoetes da sua época. (LIMA, 1988, p. 89)

Pode-se, contrariamente, afirmar que tal frequência, inclusive nas situações mais absurdas e descabidas, confirma a ironia. A repetição, a constância, a recorrência, a redundância é uma forma de caricatura. E a caricatura do procedimento do cristão português realça suas contradições e dá sustentação à ironia.

É evidente que Mendes Pinto - quer seja cristão novo, ou não - incorpora a ética cristã do proveito; mas o seu texto é um contundente libelo contra essa mesma ética.

$\mathrm{O}$ que se vê nas viagens, ou se imagina e inventa, tem por fim criticar e tentar melhorar a realidade do mundo português, do mundo cristão. Assim, as virtudes dos gentios - percebidas até mesmo por um protagonista que se pinta como tão insensível quanto aqueles a quem critica - as virtudes dos gentios são, em si mesmas, uma crítica ao comportamento europeu. Obviamente, a crítica é ao mau cristão, ou seja, como convém emendar: a todos os portugueses da época que empreenderam a aventura da conquista. Restringir a crítica seria crer que o universo dos criticáveis também fosse restrito.

Há uma passagem na Peregrinação onde o pretexto seria a crítica à religião do outro. Vejamos: "Desta sua cegueyra \& incredulidade lhe nacen os grandes desatinos, \& a grande confusão de superstições que tem entre sy". Façamos um corte e vejamos outra passagem do texto, mais adiante, onde entre tais desatinos e superstições destacam-se as - usemos uma expressão em alta - propinas "que dão aos seus sacerdotes, porque [ou: para que estes] lhes segurem grandes bems nesta vida, \& na outra riquezas de ouro infinitas, os 
quais sacerdotes lhe dão para isso hums escritos como letras de cambio." (PINTO, 1614, p. 251)

A coincidência com os hábitos cristãos e, especialmente, com a venda de indulgência pela igreja de Roma impõe ao leitor alguma reflexão em torno da ironia.

Há, de fato, um parentesco entre a escritura de Fernão Mendes Pinto e a de Jonathan Swift. Esse último, mesmo vivendo da atividade religiosa, não deixa de ver as mazelas da sua grei.

Dizer que a Peregrinação está em perfeita sintonia com o cristianismo do século XVI, como querem alguns estudiosos (revisionistas), é reduzir essa escrita literária, polissêmica e aberta à atualização do possível leitor de qualquer tempo, a mera condição de um "diário de bordo".

Conforme se sabe, o texto de Mendes Pinto foi escrito muitos anos depois das suas viagens, não obstante o relato, rico em pormenores e sugestivo de emoções recém-vividas, dê a impressão que muitas passagens foram escritas ao calor dos acontecimentos. Esse poder de sugestão é típico do texto literário, onde a ficcionalidade constrói os detalhes, onde a realidade do sujeito preenche o vazio - ou a ausência - da realidade objetiva.

Mas se a Peregrinação não contém "cousa alguma contra a nossa santa Fé", conforme a leitura do censor do Santo Ofício - esse sim perfeitamente integrado ao sistema de valores do cristianismo do século XVI e incapaz, portanto, de ler as evidências dos fatos -, se a Peregrinação não contém nada contra as convicções e os interesses dito cristãos da época, por que Mendes Pinto temia? Se é que temia. O temor, em tais circunstâncias sugere que se veja mais do que o censor alcançava - ao ver.

Quando os valores religiosos entram em cena na Peregrinação, o narradorpersonagem procura se manter imune ao encantamento e à sedução do desconhecido. Nessas circunstâncias, o ouvidor atento não ouve, o voyer contumaz não vê.

Para fugir ao rigor da censura ou ao sistema de terror instaurado pela Igreja, o texto da Peregrinação assume o discurso piedoso mais absurdo, justificando todas as atrocidades em nome de Cristo, do mesmo modo que faziam os inquisidores. Dessa forma, o narrador cerca-se de cacoetes clericais, usando o nome de Deus a toda hora e evitando críticas diretas aos hábitos portugueses.

São as evidências e os fatos objetivados que substituem a crítica aparente, como faz, na atualidade, o chamado jornalismo objetivo. Mesmo sem comentar a notícia, a mídia seleciona fatos que conduzem o leitor a um determinado posicionamento. O jornalismo 'objetivo' apenas edita o dito.

A crítica velada, disfarçada pela cuidadosa escolha dos episódios mostrados, tanto é usada nos nossos dias quanto foi experimentada no século XVI por Fernão Mendes Pinto. Afinal de contas, é a arte, a literatura, que descobre novos modos de dizer o indizível, ou aquilo que não pode ser dito.

Quando a crítica aparece na Peregrinação, ela é alegorizada em forma de crítica ao outro, ao gentio. Ou aparece em forma de louvor ao contra-senso, quando depois de roubar pessoas indefesas, os portugueses agradecem à graça de Deus, pela proteção. 
É a exposição crua dos fatos, vistos sem constrangimento, e contrapostos às piedosas expressões de beatice, que funciona como crítica; uma crítica que não aparece nas palavras do texto mas eclode no ato da leitura.

Excluída a possível natureza contestatória do livro, como querem os revisionistas, continuaria inexplicado o longo tempo decorrido entre a finalização do texto e sua impressão. Somente vinte anos depois da morte do autor a obra veio a lume.

O temor de Mendes Pinto à repercussão da sua obra ganha sentido a partir daí, da sua consciência crítica, consciência dos recursos usados pela sua escritura. Lida a Peregrinação como um canto de louvor sincero ao cristianismo do século XVI, o autor não teria motivos de temor ao Santo Ofício. Mas ele temia; é o que os fatos indicam. Desta forma, a presença da ironia, da avaliação judicativa, ou mesmo da paródia como forma de crítica ao parodiado, continua como proposta sustentável. E fascinante.

\section{REFERÊNCIAS}

BARTHES, Roland $(1953,1972)$. Novos ensaios críticos seguidos de O grau zero da escritura. São Paulo, Cultrix, 1974.

CATZ, Rebeca. A sátira social de Fernão Mendes Pinto. Lisboa, Prelo, 1978.

CATZ, Rebecca, Fernão Mendes Pinto: Sátira e Anti-Cruz̧ada na Peregrinação, 1. ed.. Lisboa, Biblioteca Breve, 1981.

CATZ, Rebecca. A Peregrinação é um livro de filosofia moral e religiosa. Jornal de Letras Artes e Ideias, n 63, de 19 de Julho a 1 de Agosto de 1983.

LIMA, Francisco Ferreira de. O outro livro das maravilhas. A Peregrinação de Fernão Mendes Pinto. Rio de Janeiro, Relume Dumará, 1998.

PINTO, Fernão Mendes (1614). Peregrinação. Lisboa, Imprensa Nacional / Casa da Moeda, 1983. (Baseada na Edição de Adolfo Casais Monteiro, 1952-1953.)

PINTO, Fernão Mendes. Peregrinação (cotejada com a 1. ed. de 1614, leitura atualizada, introdução e anotações de Neves Águas), Lisboa, Publicações Europa-América, 1996.

REBELO, Luís de Sousa. Prefácio. In: CATZ, Rebeca. A sátira social de Fernão Mendes Pinto. Lisboa: Prelo, 1978.

SARAIVA, Antônio José. Fernão Mendes Pinto. Europa-América, 1971 (Col. Obras de A. J. S., 5). 
Recebido em: 07/03/2017 Aprovado em: 20/05/2017

Publicado em: 01/06/2017 